\title{
A IMPORTÂNCIA DO ACOMPANHAMENTO PSICOLÓGICO A MÉDICOS VETERINÁRIOS RESIDENTES
}

(The importance of psychological support to veterinary residents)

Larissa Rachel Wolf, Bruno Pedon Nunes, Rita de Cassia Maria Garcia

Universidade Federal do Paraná, Curitiba, Paraná, Brasil.

*Correspondência: larissarwolf@hotmail.com

RESUMO: O exercício da profissão da medicina veterinária é um desafio para os profissionais recém-formados. Vários profissionais, ao se formarem, ingressam em programas de residência médica, que são modalidades de ensino caracterizadas por treinamento em serviço, sob supervisão, em tempo integral, para aperfeiçoamento e especialização em determinada área da profissão. São muitos os determinantes que comprometem a saúde e a qualidade de vida dos médicos veterinários residentes. Fatores como o período de transição aluno-médico, a responsabilidade profissional, o isolamento social, privação de sono e sobrecarga de trabalho estão associados a reações psicológicas, psicopatológicas e comportamentais, tornando os médicos residentes um grupo de risco para distúrbios emocionais. Os médicos veterinários possuem uma taxa de suicídio quatro vezes superior à população geral e duas vezes superior a outros profissionais da saúde, e estão suscetíveis a distúrbios como depressão, síndrome de burnout e fadiga por compaixão. Com o objetivo de avaliar a percepção dos médicos veterinários relação à importância do acompanhamento psicológico, foi realizada uma pesquisa com médicos veterinários residentes do Hospital Veterinário da Universidade Federal do Paraná em novembro de 2017, sendo aplicado um questionário. Dezenove residentes responderam ao questionário, sendo $79 \%$ (15/19) do gênero feminino e $21 \%$ (4/19) do gênero masculino. A partir das respostas, foi constatado que $42 \%$ (8/19) dos residentes já realizavam algum tipo de acompanhamento psíquico (psicológico ou psiquiátrico). Dentre as questões vivenciadas na rotina médica, aquelas que mais traziam incômodo para os residentes foram os maus-tratos aos animais, negligência e abandono, relacionamentos interpessoais, sobrecarga de trabalho, carga horária excessiva e falta de valorização profissional. Quando questionados sobre a importância do apoio psicológico para médicos veterinários residentes, 100\% (19/19) dos respondentes afirmaram considerar importante a existência de algum tipo de acompanhamento e $84 \%$ afirmaram que utilizariam um serviço de acompanhamento psicológico caso houvesse a implementação no programa, o que demonstra a grande importância da disponibilidade deste tipo de serviço em todos os programas de residência.

Palavras-chave: residência; saúde mental; distúrbios psicológicos; psicopatologias; depressão

\section{Referências}

NOGUEIRA-MARTINS, Luiz A.; JORGE, Miguel R. Natureza e magnitude do estresse na residência médica. Revista da Associação Médica Brasileira, v. 44, n. 1, p. 28-34, 1998.

MELLANBY, Richard J. Incidence of suicide in the veterinary profession in England and Wales. Veterinary Record, v. 157, n. 14, p. 415, 2005. 